\title{
Examining the effect of exposure time on the erosive potential of sour candy
}

SADJ March 2021, Vol. 76 No. 2 p72 - p77

LS Naidoo', SC Onwubu², N Murugan³ ${ }^{3}$ S Singh ${ }^{4}$

\section{ABSTRACT}

Aim

This study aimed to evaluate the erosive potential of sour candy at a different time of exposure within a laboratorybased setting.

\section{Materials and methods}

Fifty human anterior tooth samples were randomly assigned into three groups, namely: sour candy, regular candy $A$, and deionized water $(n=15)$. Each tooth samples was exposed to a solution containing the sample groups at different time intervals. Vickers hardness tester was used to measure the surface hardness pre- and postexposure.

The mean surface hardness value measured was compared using a paired sample test $(\alpha=.05)$. Raman spectroscopy was used to study the change in the enamel structure in all sample groups.

\section{Results}

A significant difference in the surface hardness value was measured pre and post-exposure in all the sample groups $(P<0.01)$. The samples exposed to sour candy had the highest tooth surface loss. In terms of the time of exposure, it was found that prolonged exposure had a significant effect on the surface hardness $(P<0.01)$. The Raman intensity change confirmed that samples exposed to sour candy, after 2 hrs of exposure, had the highest loss of structural integrity.

\section{Author affiliations:}

1. Lesley S Naidoo: B.D.Th, Discipline of Dentistry, School of Health Sciences, University of KwaZulu-Natal (UKZN), Durban, South Africa.

ORCID Number: 0000-0002-1774-0705

2. Stanley C Onwubu: $P h D$, Chemistry, Durban University of Technology (DUT), Durban, South Africa. ORCID Number: 0000-0002-4499-1534

3. Nelisha Murugan: Msc, Microscopy and Microanalysis Unit (MMU), University of KwaZulu-Natal (UKZN), Durban, South Africa ORCID Number: 0000-0003-3936-5798

4. Shenuka Singh: $P h D$, Discipline of Dentistry, School of Health Sciences, University of KwaZulu-Natal (UKZN), Durban, South Africa.

ORCID Number: 0000-0003-4842-602X

Corresponding author: Stanley C Onwubu

Chemistry, Durban University of Technology (DUT),

Durban, South Africa.

Email:21445599@dut4life.ac.za

Author contributions:

1. Lesley S Naidoo: Principal researcher - 35\%

2. Stanley C Onwubu: Writing article $-35 \%$

3. Nelisha Murugan: Writing article $-15 \%$

4. Shenuka Singh: Advisor - $15 \%$

\section{Conclusion}

The study conclude that sour candies are very erosive and its impact enhances with time.

\section{Keywords}

Acids, erosion, tooth enamel, sour candy.

\section{INTRODUCTION}

Dental erosion is characterized by the loss of tooth substances by chemical processes mainly acids of nonbacterial origin. ${ }^{1}$ From an epidemiological perspective, dental erosion is highly considered a significant dental problem in both adults and children with a prevalence of $25.11 \%$ to $51.6 \%$, respectively. ${ }^{2}$

Moreover, studies ${ }^{3,4}$ have directly associated the onset of dental erosion with an increased in the consumption of diets that is rich in acidic content. In South Africa, for example, it is reported that diets and lifestyles are changing with significant consequences for non-communicable disease. ${ }^{5}$ The consequence of this is the high incidence of dental caries and erosion of the dentinal surface. ${ }^{6}$

Furthermore, it has been reported in the literature that several intrinsic (chronic vomiting) and extrinsic (acidic foods and drinks) factors influence the degree of erosive wear. Zero and Lussi, ${ }^{7}$ however, suggest that the frequency and duration of exposure to erosive agents are important considerations in the onset of dental erosion.

Given that the residential time of candies in the oral cavity tends to be prolonged, 8,9 the consumption of acidic candies is now recognized as a potential risk factor for the onset of dental erosion. ${ }^{10}$ Particularly, sour candies possess high adhesive properties to the tooth surface which require a better knowledge about its erosive potential. ${ }^{11,12}$

More worrisome is that the level of protection provided by saliva may not be sufficient to prevent the formation and progression of erosion. ${ }^{13}$ In an attempt to manage dental erosion, a comprehensive understanding of the role of $\mathrm{pH}$ and time plays in the onset of dental erosion will be highly useful for oral care providers. While several studies have reported that the salivary $\mathrm{pH}$ after the acidic drinks requires one to fifteen minutes to return to normal, ${ }^{14,15}$ there is, however, limited evidence on the erosive potential of sour candies on tooth enamel at different times of exposure. This study aimed to examine the erosive potential of sour candy at a different time of 
exposure within a laboratory-based setting. The hypothesis tested was that the time of exposure would have no significant impact on the prepared tooth enamel samples.

\section{MATERIALS AND METHODS}

Various brands of candy were purchased from grocery stores in Durban, South Africa. The candies were differentiated and marked as sour candy and regular candy types. The candies were subject to $\mathrm{pH}$ analysis by dissolving 1 gram candy and $5 \mathrm{ml}$ deionized water. The solution was constantly agitated at a low speed of $600 \mathrm{rpm}$ for 5 minutes. A pH meter (Starter 300, Ohaus Incorporation USA) equipped with a temperature sensor was constantly used to monitor changes in the $\mathrm{pH}$ reading. Sour candy $\mathrm{pH}$ range was predominantly between $\mathrm{pH} 2-\mathrm{pH} 3$ whilst regular candies were predominantly between $\mathrm{pH} 4-\mathrm{pH} 6$. Two popular brands of candywere selected from the candy groups; 1. Fun sour worm candy (sour candy), and 2. Hello kitty Jelly belly (regular candy).

\section{Preparation of enamel specimens}

Fifty recently extracted human anterior teeth with no visible defects or prior carious lesions were selected. The enamel specimens (approximately $6 \mathrm{~mm} \times 6 \mathrm{~mm} \times$ $3 \mathrm{~mm}$ ) were prepared using a low-speed diamond cutter after the removal of the roots. The prepared ename specimens were randomly assigned to three different groups based on candy type and $\mathrm{pH}$ (Table 1). Each sample was equally divided by placing a central indentation using a low-speed diamond bur to differentiate the surface for exposure $(n=3)$. The sample base was placed on a composite resin for stability, ease of use, and light-cured. A permanent marker was used on the resin base to identify and orientate the specimen.

The control surface (unexposed enamel surface) was pro tected using clear nail varnish (coty topcoat). Samples were subsequently immersed in each of the candy solutions $(50 \mathrm{ml})$ at the specified immersion time intervals under constant agitation (100 rpm at room temperature), then rinsed with deionized water and air-dried. The clear nail varnish was removed using acetone and rinsed again with deionized water and air-dried.

\section{Hardness test}

The surface microhardness of each sample specimen pre- and post-exposure was measured and recorded using a Vicker hardness measuring device. A $200 \mathrm{~g}$ load was used to make an indentation on the enamel surface.

Thereafter, the loaded diamond was allowed to sink and rest on the enamel surface for $15 \mathrm{~s}$. Four different measurements were obtained for each sample and the average Vickers hardness recorded used for statistical analysis.

\section{Raman Spectroscopy analysis of specimens}

The changes in the mineral content of the specimens were observed using a Raman (Perkin Elmer precisely Raman-station 400). The Raman analysis was done on all the samples with the green laser power set at $70 \mathrm{~mW}$, exposure every 10 seconds for 3 seconds at a time. Using a sampling area of $20 \times 20$ micro, five different measurements were done for each sample and the average was used for statistical analysis.

\section{Statistical analysis}

Using statistical package (SPSS v26; IBM Corp), the mean hardness value measured of the enamel specimens pre- and post-exposure were evaluated with a paired sample test $(\alpha=.05)$.

\section{RESULTS}

\section{Surface hardness}

The mean surface hardness after 2 min of exposure is shown in Table 2. A significant difference was observed pre-and post-exposure in all the sample groups. However, the samples exposed to sour candy had the highest surface loss mean difference whilst the lowest surface mean surface loss were found in specimens exposed to DW.

The mean surface hardness after 10 min of exposure is shown in Table 3. A significant difference was observed pre-and post-exposure in all the sample groups. However, the samples exposed to sour candy had the highest surface loss mean difference while the lowest was measured for the specimens exposed to DW. The mean surface hardness after 15 min of exposure is shown in Table 4. A significant difference was observed pre-and post-exposure in all the sample groups. However, the samples exposed to sour candy had the highest surface loss mean difference while the lowest was measured for the specimens exposed to DW.

The mean surface hardness after $1 \mathrm{hr}$ of exposure is shown in Table 5. A significant difference was observed pre-and post-exposure in all the sample groups. The samples exposed to sour candy had the highest surface loss mean difference. It was, however, observe that the mean difference loss measured in the specimens exposed to the candies were the same.

The mean surface hardness after $2 \mathrm{hrs}$ of exposure is shown in Table 6. A significant difference was observed pre-and post-exposure in all the sample groups. The samples exposed to sour candy had the highest surface loss mean difference while the lowest was measured for the DW.

\section{Spectroscopy assessment}

The change in the mineral content of the enamel pre-and post-exposure at a different time is given in Figure 1. There is clear evidence in the plotted subsets of the data for demineralization of the enamel as $\mathrm{pH}$ decreases (especially for sour candy (Fig 1B)), and also for the increase of demineralization with exposure time (especially at longer exposure times (Fig 1B (e)).

The demineralization evidence is in both the decrease in intensity of the primary peak (associated with PO4 
ion) around $960 \mathrm{~cm}^{-1}$ and also in the decrease of the secondary peak around $1070 \mathrm{~cm}^{-1}$ that is associated with the presence of carbonates. Hence, it can therefore be said that decrease in the peak intensity confirmed the demineralization of the tooth enamel. This was even more significant with the samples exposed to sour candy and for a longer period of time (Figure 1A (e)).

\section{DISCUSSION}

In the recent decade, there has been an increase in enamel erosion amongst adults, adolescence, and children due to the high consumption of candies. ${ }^{16}$ The purpose of this study was to examine the erosive potentials of sour candy on tooth enamel at a different time of exposure.

This study found that the $\mathrm{pH}$ of the sour candy was lower $(\mathrm{pH} 2)$ than that of the regular candy $(\mathrm{pH} 5)$. Furthermore, the study results explicitly showed that there were significant differences pre and post-exposure to sour candy, regular candies at each time of exposure.

This notwithstanding, the decrease in surface hardness was much more significant for the sour candy. The high decreased in enamel surface hardness may be attributed to the $\mathrm{pH}$ of the sour candy.

\begin{tabular}{|c|c|c|c|c|}
\hline Sample group & Brand name & $\mathrm{pH}$ & Exposure time & Type of acids \\
\hline Deionized water (control) & DW & 6.2 & \multirow{3}{*}{$2 \mathrm{~min}, 10 \mathrm{~min}, 15 \mathrm{~min}, 1 \mathrm{hr}$, and $2 \mathrm{hrs}}$. & N/A \\
\hline Sour candy & 1. Fun sour worm candy & 2 & & Citric and Lactic \\
\hline Regular candy A & 2. Hello Kitty Jelly belly & 5 & & Acid regulators \\
\hline
\end{tabular}

\begin{tabular}{|c|c|c|c|c|}
\hline Sample group & Exposure & Mean (SD) $\mathrm{Kg} / \mathrm{mm}^{2}$ & Mean difference & $p$-value \\
\hline \multirow{2}{*}{ DW } & Exposed & $350 \pm 14.7$ & -2.25 & 0.003 \\
\hline & Unexposed & $352 \pm 15.0$ & & \\
\hline \multirow{2}{*}{ Sour candy } & Exposed & $344.25 \pm 32.7$ & -15 & 0.001 \\
\hline & Unexposed & $359.25 \pm 32.7$ & & \\
\hline \multirow{2}{*}{ Regular candy } & Exposed & $398 \pm 30.3$ & -4.25 & 0.001 \\
\hline & Unexposed & $402.2 \pm 30.4$ & & \\
\hline
\end{tabular}

\begin{tabular}{|c|c|c|c|c|}
\hline Sample group & Exposure & Mean (SD) $\mathrm{Kg} / \mathrm{mm}^{2}$ & Mean difference & $p$-value \\
\hline \multirow{2}{*}{ DW } & Exposed & $394.5 \pm 25.6$ & -7.8 & 0.000 \\
\hline & Unexposed & $402.3 \pm 26.1$ & & \\
\hline \multirow{2}{*}{ Sour candy } & Exposed & $402 \pm 15.2$ & -21.8 & 0.002 \\
\hline & Unexposed & $423.8 \pm 13.0$ & & \\
\hline \multirow{2}{*}{ Regular candy } & Exposed & $382 \pm 10.6$ & -11 & 0.001 \\
\hline & Unexposed & $393.2 \pm 10.6$ & & \\
\hline
\end{tabular}

\begin{tabular}{|c|c|c|c|c|}
\hline Sample group & Exposure & Mean (SD) $\mathrm{Kg} / \mathrm{mm}^{2}$ & Mean difference & $p$-value \\
\hline \multirow{2}{*}{ DW } & Exposed & $378 \pm 39$ & -7.2 & 0.000 \\
\hline & Unexposed & $385 \pm 38.7$ & & \\
\hline \multirow{2}{*}{ Sour candy } & Exposed & $343.5 \pm 29.4$ & -22.7 & 0.014 \\
\hline & Unexposed & $366.3 \pm 23.4$ & & \\
\hline \multirow{2}{*}{ Regular candy } & Exposed & $378 \pm 39$ & -7.2 & 0.000 \\
\hline & Unexposed & $385 \pm 38.7$ & & \\
\hline
\end{tabular}

\begin{tabular}{|c|c|c|c|c|}
\hline Sample group & Exposure & Mean (SD) $\mathrm{Kg} / \mathrm{mm}^{2}$ & Mean difference & $p$-value \\
\hline \multirow{2}{*}{ DW } & Exposed & $243.5 \pm 23.9$ & -18 & 0.003 \\
\hline & Unexposed & $261.5 \pm 27.2$ & & \\
\hline \multirow{2}{*}{ Sour candy } & Exposed & $339 \pm 34.4$ & -42 & 0.001 \\
\hline & Unexposed & $381 \pm 38.8$ & & \\
\hline \multirow{2}{*}{ Regular candy } & Exposed & $384.5 \pm 12.4$ & -17.5 & 0.000 \\
\hline & Unexposed & $402.0 \pm 12.7$ & & \\
\hline
\end{tabular}

\begin{tabular}{|c|c|c|c|c|}
\hline Sample group & Exposure & Mean (SD) $\mathrm{Kg} / \mathrm{mm}^{2}$ & Mean difference & $p$-value \\
\hline \multirow{2}{*}{ DW } & Exposed & $383 \pm 16.4$ & -9.8 & 0.003 \\
\hline & Unexposed & $392.8 \pm 16.1$ & & \\
\hline \multirow{2}{*}{ Sour candy } & Exposed & $334.3 \pm 21.7$ & -50.3 & 0.000 \\
\hline & Unexposed & $384.5 \pm 23.2$ & & \\
\hline \multirow{2}{*}{ Regular candy } & Exposed & $381.5 \pm 23.9$ & -31 & 0.000 \\
\hline & Unexposed & $412.5 \pm 26$ & & \\
\hline
\end{tabular}




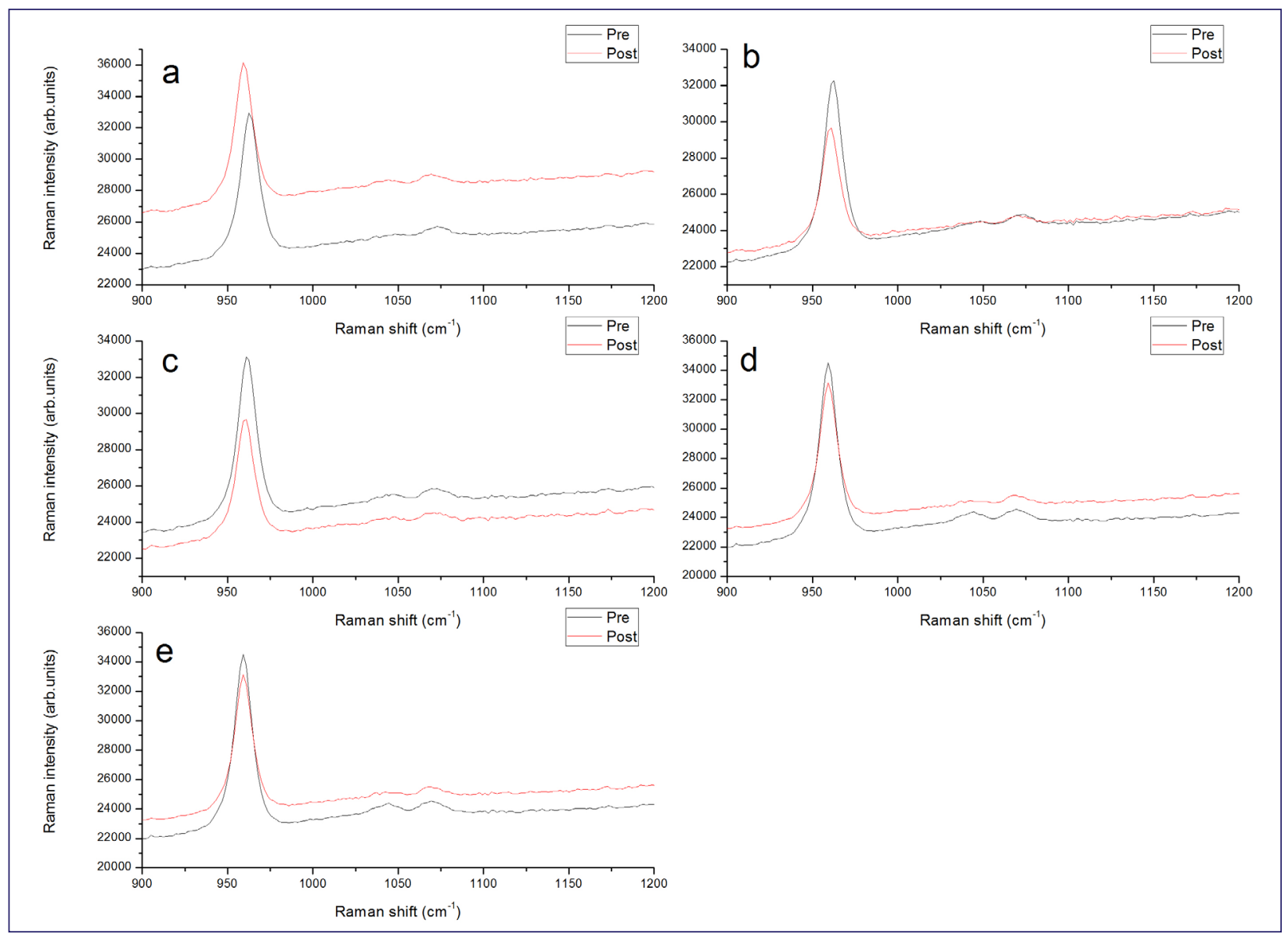

Figure 1. Raman spectroscopy shift for tooth specimens exposed (A) DW; (B) Sour candy, (C) Regular candy (a-e: time interval of exposure).

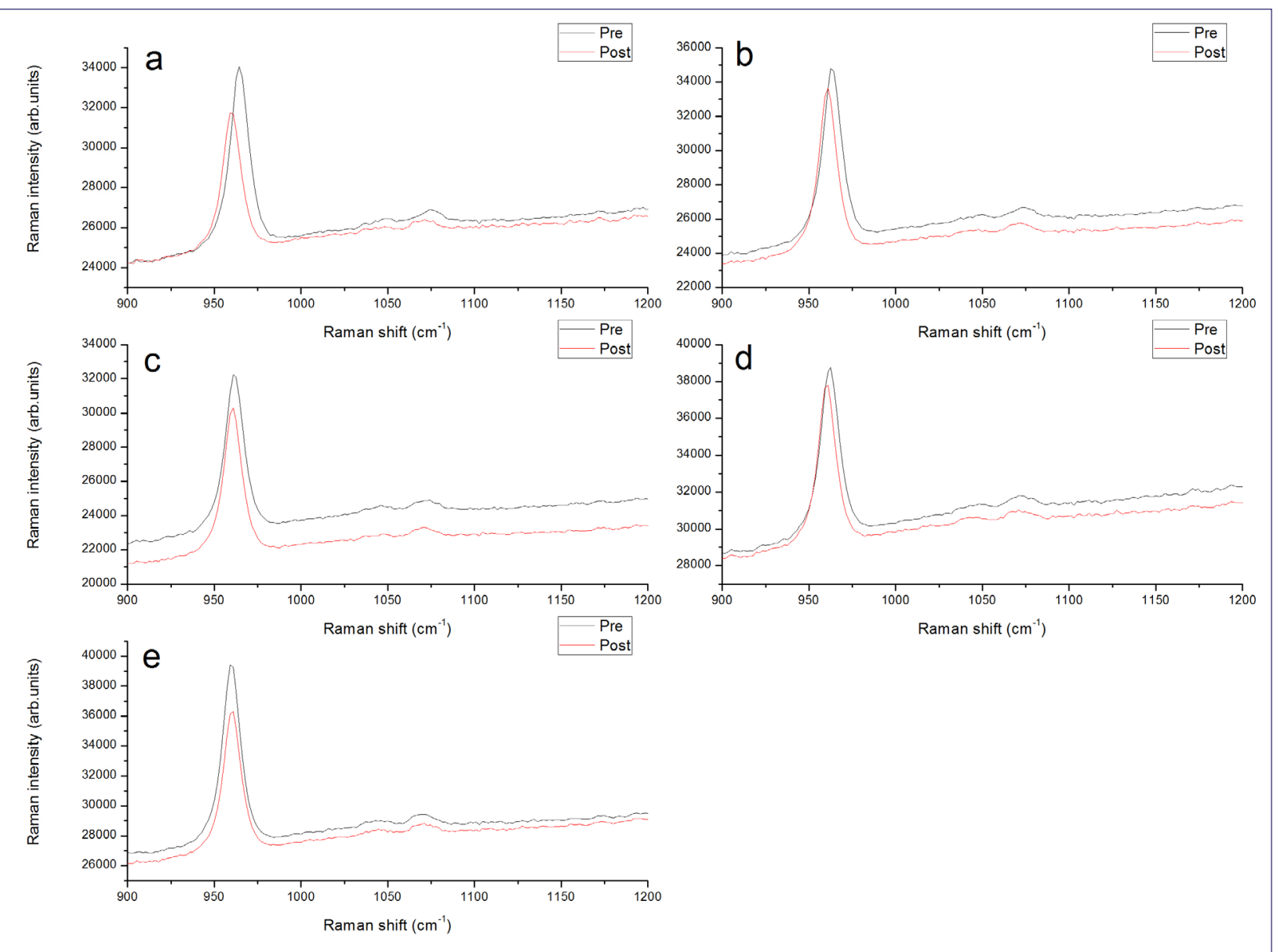

Figure 1. Raman spectroscopy shift for tooth specimens exposed (B) Sour candy (a-e: time interval of exposure). 
Of particular importance, clinical evidence has shown that salivary $\mathrm{pH}$ reaches a value as low as 2.96 immediately after the consumption of sour candy. ${ }^{16}$ This indicates that sour candy may be more erosive than the regular candies, and thus present a more detrimental effect on the enamel tooth integrity. The study findings are also in agreement with El-Marakby ${ }^{17}$ that sour substances may lead to reduce enamel surface hardness.

Apart from $\mathrm{pH}$, other authors reported that the frequency, time of exposure, the type, and concentration of acid affect enamel erosion. ${ }^{18,19}$ Consistent with this, it was observed that the enamel decrease in sample groups exposed to sour after for 2 hrs. This is particularly concerning, given that children who consumed sour candies more than twice, once daily and 2-4 times per week are nearly 24,18 , and 8 times more susceptible to dental erosion and subsequent tooth decay due to enamel vulnerability. ${ }^{16}$

Equally concerning, it was found that both regular candies at $\mathrm{pH} 5$ and 6 were significantly also erosive (Table 6). While this $\mathrm{pH}$ is near the saliva $\mathrm{pH}$, the acidic concentration in the candies may have contributed to their erosive effect.

According to Farias, de Oliveira, ${ }^{20}$ candies contains acidic components such as citric, phosphoric, ascorbic, malic, tartaric, oxalic, carbonic, and fumaric acids.

The presence of the aforementioned acids may be attributed to the post erosion measured in the candies used in this study (Table 1). This is in agreement with other studies $^{21,22}$ in that the microhardness of enamel after candy consumption decreases.

Furthermore, the spectroscopy analysis of the tooth samples pre-and post-exposure was also used to quantify the erosion effect of the candies. Onwubu, Mdlulii3 revealed that a health enamel tooth displays a strong phosphate symmetric stretching mode (v1 PO4) at $960 \mathrm{~cm}^{-1}$. In this study, it was found that the intensity of the $\mathrm{PO} 4$ peak decreased in all the samples after the erosion treatment.

This also agrees with the Kim, Son ${ }^{24}$ that a significant reduction in the intensity of peak at $960 \mathrm{~cm}^{-1}$ suggests an alteration in the structure of stoichiometric apatite during erosion. Hence, it can, therefore, be said that a decrease in the peak intensity confirmed the demineralization of the tooth enamel (Figure $1 \mathrm{~A}(\mathrm{e})$ ).

Of interest, samples exposed to deionized water also showed some degree of demineralization. It has been reported in the literature that demineralized water is highly aggressive. ${ }^{25}$ The plausible explanation for this may be due the absence of protective calcium in the water. According to Onwubu, Mdluli, ${ }^{26}$ calcium or calcium-containing materials offers protective effects against erosive attacks.

From a public health perspective, the findings from this study are highly beneficial to an oral healthcare provider in helping them to develop preventative strategies for the early detection and management of dental erosion.
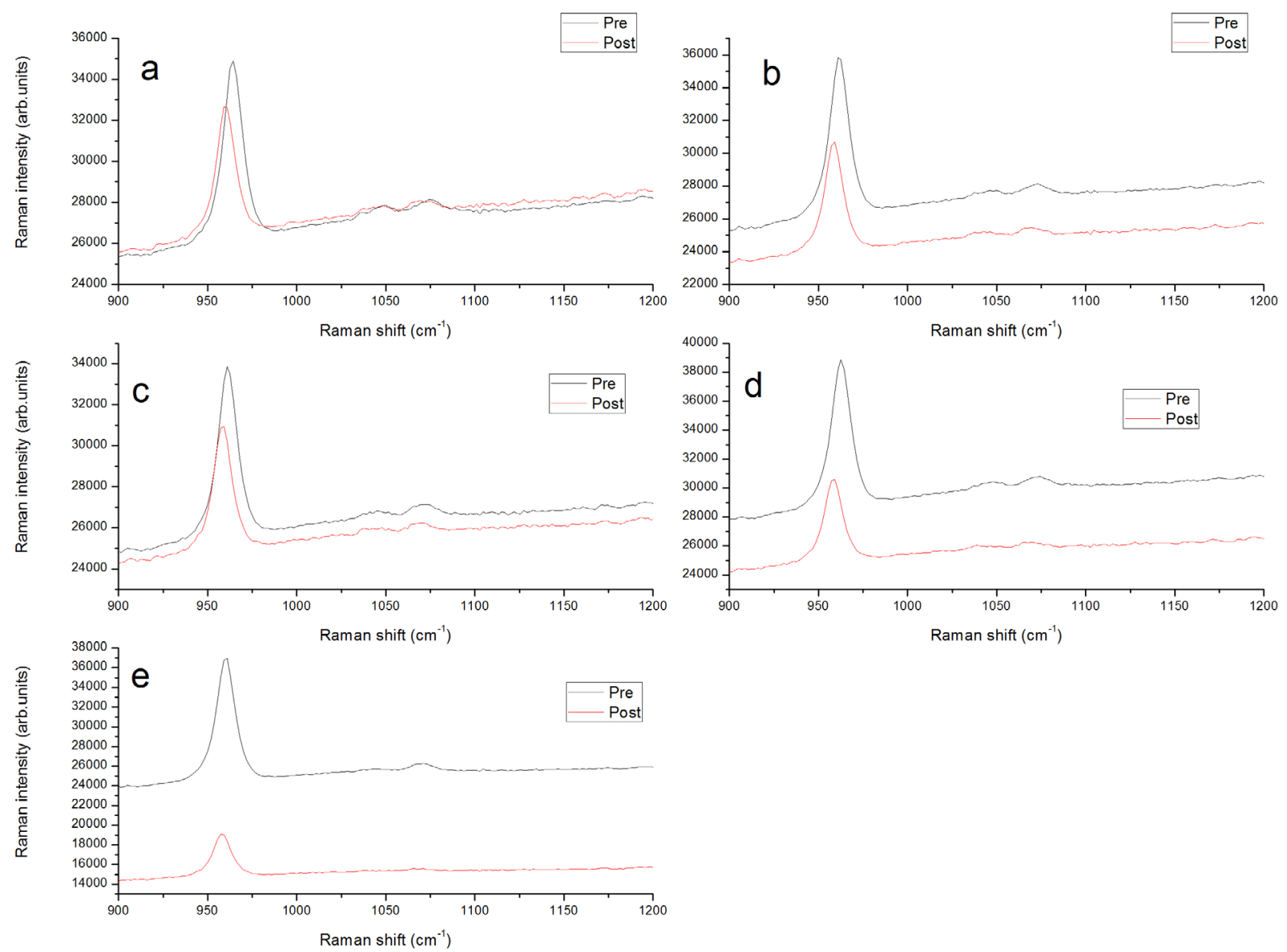

Figure 1. Raman spectroscopy shift for tooth specimens exposed (C) Regular candy (a-e: time interval of exposure). 
Hence, there is a need to evaluate clinically, the effect of sour candies and time of exposure on the surface integrity of tooth enamel. This will help formulate a strategy for a better understanding of the oral health impacts on sour candy consumption.

\section{Limitations}

The limitation arising from this study is the lack of saliva due to the in vitro nature of the study. It is generally acknowledge that intra-oral environment is complex, and therefore, the tested candies may present a different impact on the enamel compared to the static in vitro study. Future study will therefore explore the possibility of assessing the erosive effects of sour candies in a more nature vivo or In situ settings. This would help in understanding the mechanism and associated with enamel dissolution from the consumption of sour candies.

\section{CONCLUSION}

In light of the study results, this study suggests that candies, particularly the sour types, present a worrisome impact on the integrity of the tooth structure. It was found that erosive characteristics of the sour candy increase with the duration of exposure time. This is particularly concerning for oral health care provider in the management of tooth erosion amongst children that are a frequent consumer of acidic candies. Consequently, it is recommended that oral care providers advise their patients on the dangers of frequent and prolonged consumption of sour candies.

\section{Acknowledgment}

The authors acknowledge the financial support from the National Research Foundation of South Africa (Grant Number: 129492). The authors also acknowledge the technical support offered by Prof Karin Pruessner: School of Chemistry and Physics, University of KwaZulu-Natal (UKZN), Durban, South Africa.

\section{Declaration}

No conflict of interest declared.

\section{References}

1. Buzalaf MAR, Hannas AR, Kato MT. Saliva and dental erosion. J Appl Oral Sci. 2012; 20(5): 493-502.

2. Lazzaris M, Farias MMAG, Araújo SM, Schmitt BHE, Silveira EG. Erosive potential of commercially available candies. Pesqui Bras Odontopediatria Clin Integr. 2015; 15(1): 7-12.

3. Farias MMAG, Silveira EGd, Schmitt BHE, Araújo SMd, Baier IBA. Prevalência da erosão dental em crianças e adolescentes brasileiros. Salusvita. 2013; 32(2).

4. Murakami C, Oliveira LB, Sheiham A, Corrêa MSNP, Haddad AE, Bönecker M. Risk indicators for erosive tooth wear in Brazilian preschool children. Caries Res. 2011; 45(2): $121-9$.

5. Stacey N, van Walbeek C, Maboshe M, Tugendhaft A, Hofman K. Energy drink consumption and marketing in South Africa. Prev. Med. 2017; 105: S32-S6.

6. Pinto SC, Bandeca MC, Silva CN, Cavassim R, Borges AH, Sampaio JE. Erosive potential of energy drinks on the dentine surface. BMC Res. Notes. 2013; 6(1): 67.
7. Zero D, Lussi A. Dental erosion. Monogr Oral Sci. 2006; 20: 100-5.

8. Stewart KF, Fairchild RM, Jones RJ, Hunter L, Harris C, Morgan MZ. Children's understandings and motivations surrounding novelty sweets: a qualitative study. Int. J. Paediatr. Dent. 2013; 23(6): 424-34.

9. Brand H, Gambon D, Paap A, Bulthuis M, Veerman E, Amerongen AN. The erosive potential of lollipops. Int. Dent J. 2009; 59(6): 358-62.

10. Nahas Pires Correa MS, Nahás Pires Corrêa F, Nahas Pires Correa JP, Murakami C, Mendes FM. Prevalence and associated factors of dental erosion in children and adolescents of a private dental practice. International J Paediatr Dent. 2011; 21(6): 451-8.

11. Aljawad A. Dental public health implications of novelty sweets consumption in children: Cardiff University. 2016.

12. Aljawad A, Morgan MZ, Fairchild R, Rees J. Investigation of the erosive potential of sour novelty sweets. Br. Dent. J. 2017; 222(8): 613

13. Wagoner SN, Marshall TA, Qian F, Wefel JS. In vitro enamel erosion associated with commercially available original-flavor and sour versions of candies. J Am Dent Assoc. 2009; 140(7): 906-13.

14. Lussi A, von Salis-Marincek M, Ganss C, Hellwig E, Cheaib Z, Jaeggi $\mathrm{T}$. Clinical study monitoring the $\mathrm{pH}$ on tooth surfaces in patients with and without erosion. Caries Res. 2012; 46(6): 507-12.

15. Turssi CP, Silva CS, Bridi EC, Amaral F, Franca F, Basting RT. Kinetics of salivary $\mathrm{pH}$ after acidic beverage intake by patients undergoing orthodontic treatment. Gen. Dent. 2015; 63(3): 26-30.

16. dos Reis Oliveira PR, Amaral FLB, França FMG, Basting RT, Turssi CP. Sour Gummy Candies and their Effect on Salivary pH kinetics. Pesqui Bras Odontopediatria Clin Integr. 2018; 18(1): 3866

17. El-Marakby AM. Surface hardness assessment of tooth Substrates and Different Esthetic Restorative Materials after Immersion in Different Acidic media. Int J Dent \& Oral Heal. 2018; 4(11): 178-83.

18. West $\mathrm{N}$, Hughes J, Addy M. The effect of $\mathrm{pH}$ on the erosion of dentine and enamel by dietary acids in vitro. $\mathrm{J}$ Oral Rehabil. 2001; 28(9): 860-4.

19. Barbour ME, Lussi A. Erosion in relation to nutrition and the environment. Erosive Tooth Wear. 25: Karger Publishers. 2014; 143-54.

20. Farias MMAG, de Oliveira MML, Schmitt BHE, da Silveira EG, de Araújo SM. Erosive potential of sugar-free hard candies dissolved in water and artificial saliva. Braz J Oral Sci. 2016; 15(1): $75-8$

21. Mudumba VL, Muppa R, Srinivas N, Kumar DM. Evaluation and comparison of changes in microhardness of primary and permanent enamel on exposure to acidic center-filled chewing gum: an in vitro study. Int J Clin Pediatr Dent. 2014; 7(1): 24.

22. Bolan M, Ferreira M, Vieira R. Erosive effects of acidic center-filled chewing gum on primary and permanent enamel. $J$ Indian Soc Pedod Prev Dent. 2008; 26(4): 149.

23. Onwubu SC, Mdluli PS, Singh S, Nyembe S, Thakur R. An in situ evaluation of the protective effect of nano eggshell/ titanium dioxide against erosive acids. Int J Dent. 2018.

24. Kim I-H, Son JS, Min BK, Kim YK, Kim K-H, Kwon T-Y. A simple, sensitive and non-destructive technique for characterizing bovine dental enamel erosion: attenuated total reflection Fourier transform infrared spectroscopy. Int J Oral Sci. 2016; 8(1): 54-60.

25. Kozisek $F$. Health risks from drinking demineralised water. Nutr in Drinking Water, 2005; 1(1): 148-163.

26. Onwubu SC, Mdluli PS, Singh S. Evaluating the buffering and acid-resistant properties of eggshell-titanium dioxide composite against erosive acids. J Appl Biomater Funct Mater. 2019; 17(1): 1-7. 